Case Report

\title{
Granulomatous Interstitial Nephritis Presenting as Hypercalcemia and Nephrolithiasis
}

\author{
Saika Sharmeen, ${ }^{1}$ Esra Kalkan, ${ }^{1}$ Chunhui Yi, ${ }^{2}$ and Steven D. Smith ${ }^{3}$ \\ ${ }^{1}$ Department of Medicine, Mount Sinai St. Luke's-Roosevelt Hospital Center, New York, NY 10025, USA \\ ${ }^{2}$ Department of Pathology, Mount Sinai St. Luke's-Roosevelt Hospital Center, New York, NY 10025, USA \\ ${ }^{3}$ Department of Medicine, Division of Nephrology, Mount Sinai St. Luke's-Roosevelt Hospital Center, New York, NY 10025, USA
}

Correspondence should be addressed to Saika Sharmeen; ssharmeen@chpnet.org

Received 30 November 2015; Accepted 29 December 2015

Academic Editor: Ze’ev Korzets

Copyright (C) 2016 Saika Sharmeen et al. This is an open access article distributed under the Creative Commons Attribution License, which permits unrestricted use, distribution, and reproduction in any medium, provided the original work is properly cited.

\begin{abstract}
We report a case of acute kidney injury as the initial manifestation of sarcoidosis. A 55-year-old male was sent from his primary care physician's office with incidental lab findings significant for hypercalcemia and acute kidney injury with past medical history significant for nephrolithiasis. Initial treatment with intravenous hydration did not improve his condition. The renal biopsy subsequently revealed granulomatous interstitial nephritis (GIN). Treatment with the appropriate dose of glucocorticoids improved both the hypercalcemia and renal function. Our case demonstrates that renal limited GIN due to sarcoidosis, although a rare entity, can cause severe acute kidney injury and progressive renal failure unless promptly diagnosed and treated.
\end{abstract}

\section{Background}

Granulomatous interstitial nephritis (GIN) is a rare cause of acute kidney injury (AKI). Causes of GIN include sarcoidosis, drugs (NSAIDs, antibiotics), and infections (mycobacterial, fungal, bacterial, and viral). Renal involvement as an initial manifestation of sarcoidosis is another rare entity. Renal failure commonly ranges from $0.7 \%$ to $4.3 \%$ in cases series of patients with previously identified sarcoidosis [1]. The majority of sarcoid related renal failure in these cases is due to two pathologic processes: (1) nephrocalcinosis with or without nephrolithiasis and (2) interstitial nephritis with or without granulomas. We report a case of GIN causing acute kidney injury as the initial presentation of sarcoidosis.

\section{Clinical Case}

A 55-year-old man was sent from his primary care physician's office with incidental findings of severe hypercalcemia and acute kidney injury (AKI). His medical history was significant for nephrolithiasis and ureteral stone removal one year prior to presentation at which time the serum creatinine was $2.05 \mathrm{mg} / \mathrm{dL}$ with a calcium of $10.5 \mathrm{mg} / \mathrm{dL}$. No further work-up was performed at that time. On presentation he was not taking any medications or using alcohol, tobacco, or illicit drugs. He had no prior surgeries. He denied cough, shortness of breath, polyuria, polydipsia, bone pain, and abdominal pain but complained of chronic low back pain and a $20 \mathrm{lb}$ weight loss over the previous several months. The blood pressure was $165 / 102 \mathrm{mmHg}$, heart rate was 80 , and he was afebrile. Physical exam was otherwise unremarkable with a clear chest, no peripheral lymphadenopathy, no rash, and no edema. Laboratories (Table 1) were remarkable for $\mathrm{Ca} 13.5 \mathrm{mg} / \mathrm{dL}$, creatinine $7.6 \mathrm{mg} / \mathrm{dL}$, and phosphorus $7.4 \mathrm{mg} / \mathrm{dL}$. Urinalysis showed calcium-oxalate crystals with 4-10 RBCs/HPF with normal morphology and the urine albumin/creatinine ratio was normal at $24 \mathrm{mg} / \mathrm{g}$. Evaluation of the hypercalcemia revealed the following: PTH < 3 (11-67 pg/mL), 25-hydroxyvitamin D 23.8 (30-95 ng/mL), 1,25-dihydroxyvitamin D $79(18-72 \mathrm{pg} / \mathrm{mL})$, and angiotensin converting enzyme (ACE) level 82 (9-67 U/L) (Table 2). Serum and urine immunofixations did not detect a monoclonal protein. A skeletal survey showed no lytic or blastic osseous lesions. Thyroid function tests were normal. His chest X-ray was negative and PFTs (pulmonary function tests) were normal but a computed tomography (CT) scan 


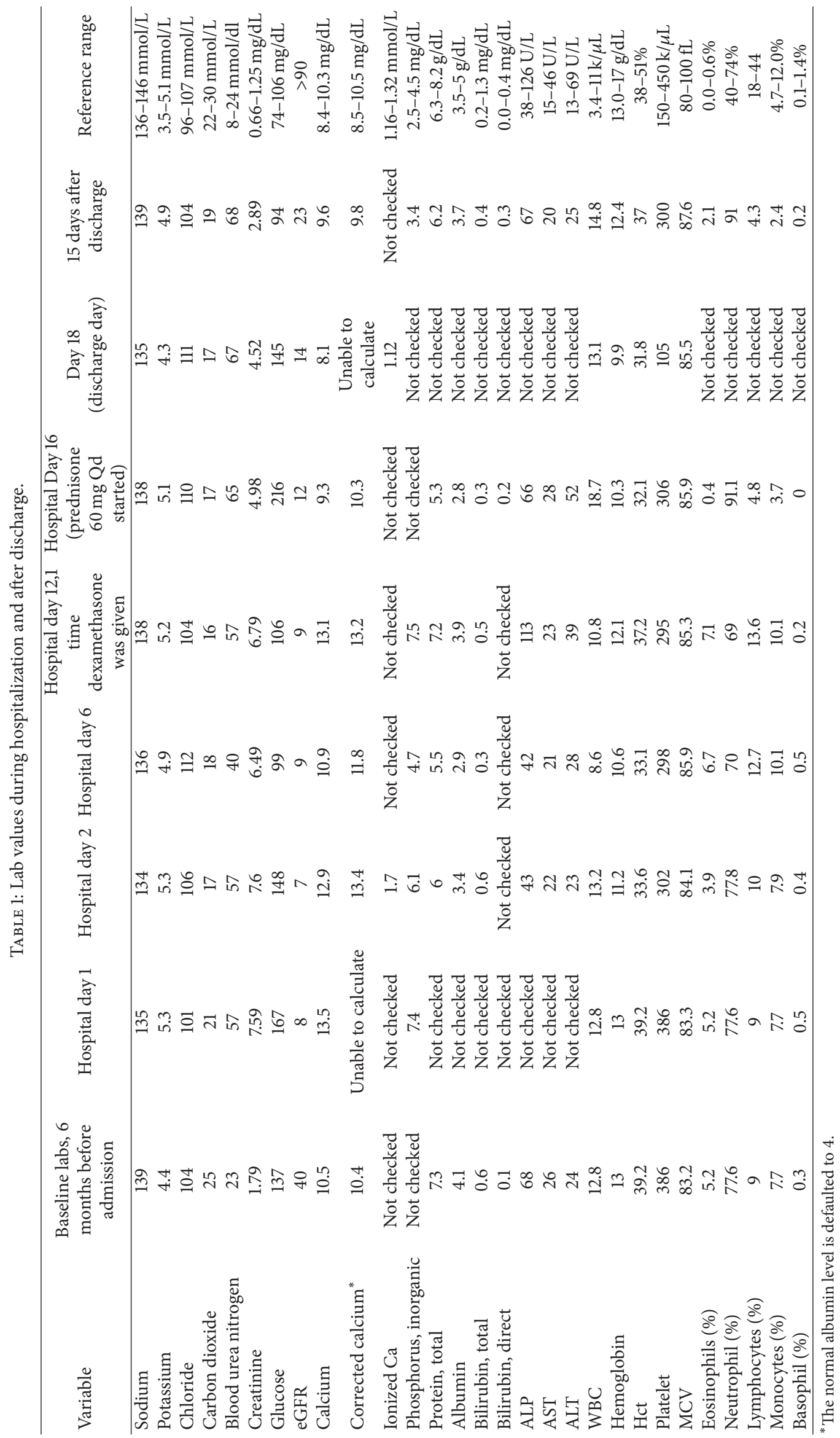


TABLE 2: Lab values.

\begin{tabular}{|c|c|c|}
\hline Variable & Measurement & Reference range \\
\hline $\mathrm{LDH}$ & 478 & 313-618 U/L \\
\hline Creatinine kinase & 40 & $55-170$ \\
\hline Cholesterol, total & 187 & $<200 \mathrm{mg} / \mathrm{dL}$ \\
\hline $\mathrm{HDL}$ & 28 & $>40 \mathrm{mg} / \mathrm{dL}$ \\
\hline LDL & 87 & $<130 \mathrm{mg} / \mathrm{dL}$ \\
\hline Cholesterol/HDL ratio & 6.7 & $0.0-4.9$ \\
\hline Triglycerides & 362 & $<151 \mathrm{mg} / \mathrm{dL}$ \\
\hline ESR & 26 & $1-13 \mathrm{~mm} / \mathrm{hr}$ \\
\hline CRP & Not checked & \\
\hline ACE, before steroid treatment & 82 & $9-67 \mathrm{U} / \mathrm{L}$ \\
\hline ACE, after steroid treatment & 24 & $9-67 \mathrm{U} / \mathrm{L}$ \\
\hline Vit D, 25 hydroxy & 27.8 & $30-95 \mathrm{bng} / \mathrm{mL}$ \\
\hline Vit D, 1,25 hydroxy, before steroid treatment & 79 & $18-72 \mathrm{pg} / \mathrm{mL}$ \\
\hline Vit D, 1,25 hydroxy, after steroid treatment & 19 & $18-72 \mathrm{pg} / \mathrm{mL}$ \\
\hline PTH, intact & 3.72 & $11-67 \mathrm{pg} / \mathrm{mL}$ \\
\hline ANA & Negative & Negative \\
\hline Immunofixation, serum & Polyclonal pattern & \\
\hline IgG, serum & 1330 & $700-1600 \mathrm{mg} / \mathrm{dL}$ \\
\hline IgA, serum & 187 & $70-400 \mathrm{mg} / \mathrm{dL}$ \\
\hline IgM, serum & 44 & $40-230 \mathrm{mg} / \mathrm{dL}$ \\
\hline Immunofixatin elec., urine & Polyclonal IGG and polyclonal light chains & \\
\hline Protein, random urine & 10 & $\mathrm{mg} / \mathrm{dL}$ \\
\hline $\mathrm{C} 3$ & 119 & $90-180 \mathrm{mg} / \mathrm{dL}$ \\
\hline $\mathrm{C} 4$ & 22 & $10-40 \mathrm{mg} / \mathrm{dL}$ \\
\hline Quantiferon-Tb gold & Indeterminate & \\
\hline Mitogen-nil & 0.16 & $\mathrm{IU} / \mathrm{ML}$ \\
\hline NIL & 0.03 & IU/ML \\
\hline TB Ag-nil & 0 & IU/ML \\
\hline $\mathrm{ASO} \mathrm{Ab}$ & 46 & $>200 \mathrm{IU} / \mathrm{ML}$ \\
\hline \multicolumn{3}{|l|}{ ANCA vasculitides } \\
\hline Proteinase $3 \mathrm{Ab}$ & $<1.0$ & $<1.0$ \\
\hline Myeloperoxidase Ab & $<1.0$ & $<1.0$ \\
\hline Hep A Ab, IgM & Nonreactive & Nonreactive \\
\hline Hep A Ab, total & Reactive & Nonreactive \\
\hline Hep B sAg & Negative & Negative \\
\hline Hep B Core Ab, total & Reactive & Nonreactive \\
\hline Hep BS ab & Reactive & Nonreactive \\
\hline HepC Ab & Negative & Negative \\
\hline HIV 1/2 Ab screen, rapid & Nonreactive & Nonreactive \\
\hline HgbAlc & 6.9 & $4.2-5.9 \%$ \\
\hline Urine culture & Negative & Negative \\
\hline \multicolumn{3}{|l|}{ Urine chemistry } \\
\hline Protein, random urine & 21 & $\mathrm{mg} / \mathrm{dL}$ \\
\hline Microalbumin, random, urine & 2.4 & $\mathrm{mg} / \mathrm{dL}$ \\
\hline Sodium, random, urine & 105 & $30-90 \mathrm{mmol} / \mathrm{L}$ \\
\hline Potassium, random, urine & 14.9 & $\mathrm{mmol} / \mathrm{L}$ \\
\hline Calcium, random, urine & 11.4 & $\mathrm{mg} / \mathrm{dL}$ \\
\hline Thyroxine, free & 0.61 & $0.8-1.5 \mathrm{ng} / \mathrm{dL}$ \\
\hline TSH & 1.038 & $0.4-4.2 \mu \mathrm{IU} / \mathrm{mL}$ \\
\hline PSA free & 0.9 & $\mathrm{ng} / \mathrm{mL}$ \\
\hline PSA percent free & 43 & $>25 \%$ \\
\hline Total PSA & 2.1 & $\leq 4.0$ \\
\hline
\end{tabular}



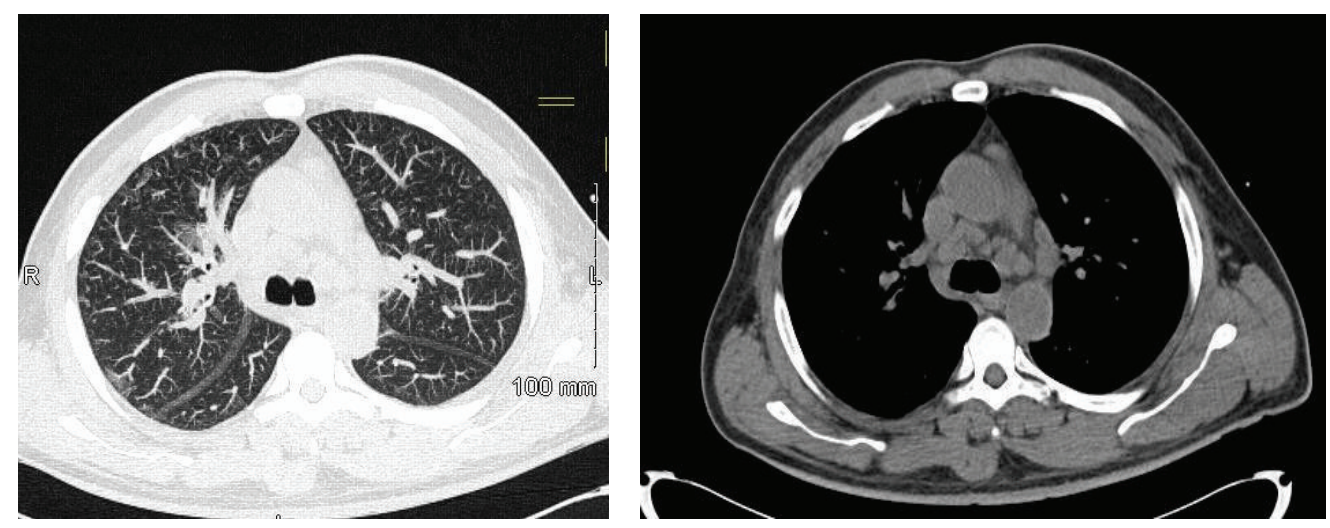

FIGURE 1: CT chest without IV contrast. Computed tomography without intravenous contrast showing mediastinal and hilar adenopathy.

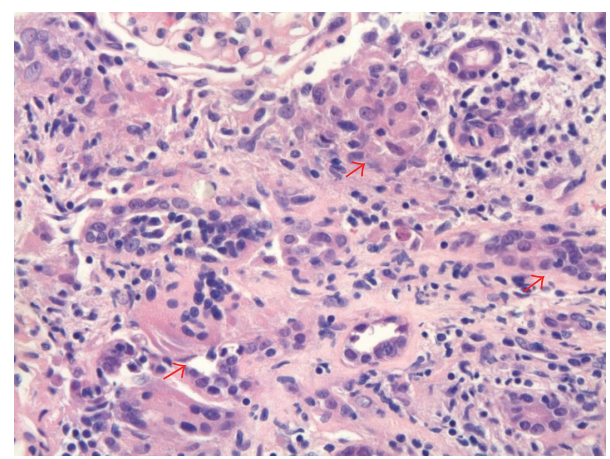

FIGURE 2: Renal Biopsy. Noncaseating granulomatous inflammation. Aggregation of epithelioid histiocytes aggregation (arrows), mixed with lymphocytes, forming granuloma. Hematoxylin and eosin (HE) stain 400x.

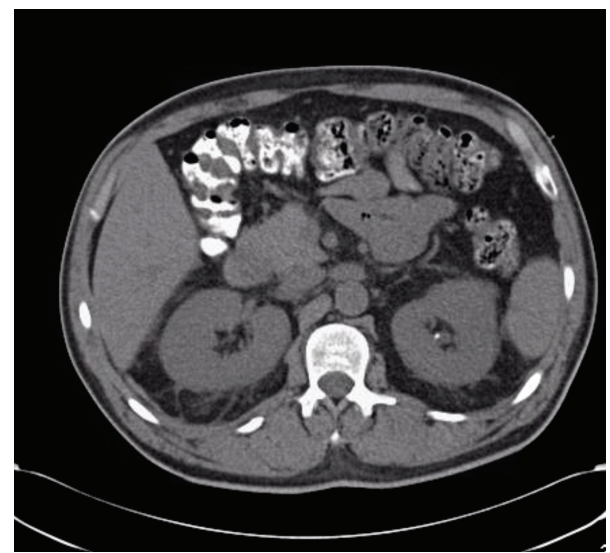

FIGURE 3: CT of abdomen and pelvis without IV contrast. CT of abdomen and pelvis without IV contrast showing a $3 \mathrm{~mm}$ nonobstructing left renal calculus with normal size kidneys and no nephrocalcinosis.

of the chest without contras showed mediastinal and hilar lymphadenopathy (Figure 1). An abdominal and pelvic CT showed a $3 \mathrm{~mm}$ nonobstructing left renal calculus with normal size kidneys and no nephrocalcinosis (Figure 3). Renal biopsy (Figure 2) showed granulomatous interstitial nephritis with diffuse interstitial inflammation with focal noncaseating granulomas. Acid-Fast Bacillus (AFB) and Grocott-Gomori's stain were negative for mycobacteria or fungal elements. Immunofluorescent microscopy demonstrated no significant staining for IgG, IgA, IgM, C3, Clq, kappa, lambda light chains, or fibrinogen. A diagnosis of sarcoid was made. The patient was initially treated with intravenous normal saline with improvement in serum calcium but no improvement in his serum creatinine. His calcium rebounded. There was suspicion for intrinsic renal disease as opposed to renal failure based on these findings. The patient was then started on prednisone $40 \mathrm{mg} /$ day and the decision was made to obtain renal biopsy for definitive diagnosis. Once the renal biopsy results showed GIN, the patient was started on IV methylprednisone $60 \mathrm{mg} / \mathrm{d}$ for three days after which oral prednisone was continued at $1 \mathrm{mg} / \mathrm{kg} /$ day with slow taper planned over 12-18 months. With the addition of the higher dose of steroids his calcium normalized to $8.6 \mathrm{mg} / \mathrm{dL}$ and the creatinine decreased to $4.5 \mathrm{mg} / \mathrm{dL}$ on discharge. Six months after discharge his creatinine improved to $2.55 \mathrm{mg} / \mathrm{dL}$ and has remained stable with a normal serum calcium. With steroid treatment the 1,25-dihydroxyvitamin D level decreased to 19 $(18-72 \mathrm{pg} / \mathrm{mL})$ and ACE level normalized at 24 (9-67 U/L).

\section{Discussion}

Sarcoidosis is a systemic disease of unknown cause that is characterized by the formation of immune granulomas in various organs, mainly the lungs and the lymphatic system [2]. Sarcoidosis can involve any organ but in more than 90 percent of patients it manifests with pulmonary involvement. Respiratory symptoms include cough, shortness of breath, and chest discomfort [3]. Most patients with GIN due to sarcoidosis present with extrarenal manifestations such as pulmonary, skin, or eye involvement $[4,5]$. However, there are a few series reporting sarcoid GIN without extrarenal involvement [6-8]. Our patient did not have any respiratory symptoms and had a normal chest X-ray in addition to normal PFTs. His chest CT showed asymptomatic mediastinal and hilar lymphadenopathy. Renal failure commonly ranges from $0.7 \%$ to $4.3 \%$ of cases in previous reported clinical series of patients with sarcoidosis but renal failure from GIN itself is 
rare $[1,9]$. A previous study found that 46 of $9,779(0.5 \%)$ renal biopsy specimens had GIN [10]. The pathology contributing to AKI from GIN in sarcoidosis is thought to be due to noncaseating granulomatous inflammation, which is composed of a central follicle of macrophages, epithelioid cells, and multinucleated giant cells $[9,11,12]$.

Hypercalcemia, a well-known metabolic complication of sarcoidosis, is only found in 10-20 percent of patients and can directly cause acute kidney injury from renal vasoconstriction and volume depletion as a result of nephrogenic diabetes insipidus [13]. Hypercalcemia is due to overproduction of 1,25-dihydroxy vitamin $\mathrm{D}$. The normal conversion of 25 hydroxyvitamin $\mathrm{D}$ to 1,25 -dihydroxyvitamin $\mathrm{D}$ (calcitriol) occurs in the kidney through 1- $\alpha$ hydroxylase, a cytochrome p 450 enzyme $[9,14]$. In sarcoidosis and other granulomatous diseases pulmonary macrophages express 1- $\alpha$ hydroxylase, which is often resistant to negative feedback mechanisms causing overproduction of 1,25-(OH)2-D3 [9, 15] leading to increased calcium uptake by the gut. Adams et al. demonstrated that 1,25-(OH)2-D3 is the hypercalcemia-causing factor in sarcoidosis and that macrophages from patients with sarcoidosis are the synthetic source of hormone in the disease. Mason et al. identified a similar metabolite in preparations of sarcoid granulomas incubated with 25-OH-D [11, 16, 17]. In patients with sarcoid, hypercalciuria is three times more common than hypercalcemia $[11,18]$ with a frequency in some studies as high as 60\% [19]. Both can lead to acute and chronic kidney injury in sarcoidosis by causing nephrolithiasis and nephrocalcinosis. Hypercalcemia and hypercalciuria contribute to the formation of calcium oxalate crystals which was likely the cause of nephrolithiasis in our patient. Interstitial calcium oxalate deposition is also seen in association with granulomas in sarcoidosis [20].

The differential diagnosis of hypercalcemia was initially broad for our patient and included hyperparathyroidism, malignancy related (multiple myeloma, lymphoma, PTHrp associated malignancy, and metastatic bone disease), infections such as tuberculosis, sarcoid, and vitamin D intoxication. Laboratory assessment narrowed the differential with an appropriately suppressed PTH and a low 25-hydroxyvitamin $\mathrm{D}$ level. The negative serum and urine immunofixations and absence of lytic or blastic lesions on a skeletal survey made malignancy less likely. The elevated ACE and 1,25dihydroxyvitamin D level made sarcoid a strong possibility but lymphomas can also cause increased production of 1,25D. Intrinsic renal disease was higher on the differential rather than renal failure from nephrocalcinosis based on the following reasons: (1) while the hypercalcemia was slowly improving with intravenous hydration, the serum creatinine did not improve. (2) the CT of the abdomen and pelvis showed a $3 \mathrm{~mm}$ nonobstructing left renal calculus with normal size kidneys and no nephrocalcinosis (Figure 3). Moreover, the renal biopsy was required for definitive diagnosis. In sarcoidosis, with the exception of Löfgren's syndrome, all other suspected cases require a biopsy specimen to establish diagnosis from the involved organ that is most easily accessed [21]. In our patient, the involved organ was the kidney. Since the patient had renal symptoms and no pulmonary symptoms (PFTs were normal and there were no clinical pulmonary symptoms) or skin involvement, the decision was made to proceed with a renal biopsy. It was ultimately the renal biopsy which demonstrated GIN in the absence of another cause that led to a diagnosis and an effective treatment plan.

The primary treatment option for GIN due to sarcoidosis is glucocorticoid therapy. Renal limited sarcoidosis with GIN is a rare occurrence but several case reports suggest that these patients do well with corticosteroid treatment [22-24] although Ikeda et al. report a case of GIN due to sarcoidosis requiring dialysis [25]. Early diagnosis and treatment may be necessary to prevent progression. Robson et al. hypothesized that idiopathic granulomatous interstitial nephritis may actually represent a renal-limited form of sarcoid. It may be associated with hypercalcemia and an elevated serum angiotensin-converting enzyme and usually responds to treatment with corticosteroids. They describe a number of patients with biopsy proven GIN without extrarenal sarcoid who also presented with hypercalcemia and renal failure all of whom responded well to steroids [26]. Hilderson et al. present a detailed overview of current treatment options for renal sarcoid with hypercalcemia. They highlight the fact that treatment guidelines are lacking and that a uniform approach is needed in treating these patients. Variation exists between the treatment of hypercalcemia in sarcoidosis and GIN sarcoidosis. Hypercalcemia in sarcoidosis is initially treated with IV saline hydration followed by prednisone at a dose of $0.3-0.5 \mathrm{mg} / \mathrm{kg}$ once daily with a maintenance dose of $5-10 \mathrm{mg} /$ day and the total duration of treatment being at least 12 months. However, for GIN sarcoidosis, they suggest three days of intravenous methylprednisolone followed by oral prednisone $1 \mathrm{mg} / \mathrm{kg} / \mathrm{d}$ in patients with major organ impairment. The dose of steroids may vary depending on severity of disease with total duration of treatment being 18 24 months including a steroid taper. In cases of glucocorticoid failure or contraindications, immunosuppressive agents such as azathioprine or mycophenolate mofetil have been used. In cases of steroid resistant sarcoidosis and when at least one other immunosuppressive agent has been tried, TNFalpha inhibitors have shown promise [27, 28]. Our patient was initially started on prednisone $40 \mathrm{mg}$ per day while awaiting the results of the renal biopsy; once the biopsy results showed GIN the patient's treatment was tailored towards the diagnosis with significant improvement in overall condition. Thus, a renal biopsy should be performed when the suspicion for renal sarcoidosis is high without any other organ involvement in order to make a definitive diagnosis and guide management.

In conclusion, sarcoidosis is a disease involving multiple different organs including the kidney. Acute kidney injury as the initial presentation of sarcoidosis as was seen in our case is a rare entity. It is necessary to combine clinical presentation, laboratory results, and renal pathology to make a correct diagnosis which often responds well to treatment with steroids.

\section{Conflict of Interests}

The authors declare that there is no conflict of interests regarding the publication of this paper. 


\section{References}

[1] M. Mahévas, F. X. Lescure, J.-J. Boffa et al., "Renal sarcoidosis: clinical, laboratory, and histologic presentation and outcome in 47 patients," Medicine, vol. 88, no. 2, pp. 98-106, 2009.

[2] D. Valeyre, A. Prasse, H. Nunes, Y. Uzunhan, P.-Y. Brillet, and J. Müller-Quernheim, "Sarcoidosis," The Lancet, vol. 383, no. 9923, pp. 1155-1167, 2014.

[3] A. S. Morgenthau and M. C. Iannuzzi, "Recent advances in sarcoidosis," Chest, vol. 139, no. 1, pp. 174-182, 2011.

[4] N. Joss, S. Morris, B. Young, and C. Geddes, "Granulomatous interstitial nephritis," Clinical Journal of the American Society of Nephrology, vol. 2, no. 2, pp. 222-230, 2007.

[5] A. Ikeda, S. Nagai, M. Kitaichi et al., "Sarcoidosis with granulomatous interstitial nephritis: report of three cases," Internal Medicine, vol. 40, no. 3, pp. 241-245, 2001.

[6] T. Hannedouche, G. Grateau, L. H. Noel et al., "Renal granulomatous sarcoidosis: report of six cases," Nephrology Dialysis Transplantation, vol. 5, no. 1, pp. 18-24, 1990.

[7] P. Nagaraja and M. R. Davies, "Granulomatous interstitial nephritis causing acute renal failure: a rare presenting feature of sarcoidosis," QJM, vol. 107, no. 6, pp. 467-469, 2014.

[8] J. Rema, M. Carvalho, R. Vaz et al., "Acute renal failure as a form of presentation of sarcoidosis in a young adult: a case report," Journal of Medical Case Reports, vol. 8, no. 1, article 274, 2014.

[9] V. Manjunath, G. Moeckel, and N. K. Dahl, "Acute kidney injury in a patient with sarcoidosis: hypercalciuria and hypercalcemia leading to calcium phosphate deposition," Clinical Nephrology, vol. 80, no. 2, pp. 151-155, 2013.

[10] V. Bijol, G. P. Mendez, V. Nosé, and H. G. Rennke, "Granulomatous interstitial nephritis: a clinicopathologic study of 46 cases from a single institution," International Journal of Surgical Pathology, vol. 14, no. 1, pp. 57-63, 2006.

[11] P. D. Thomas and G. W. Hunninghake, "Current concepts of the pathogenesis of sarcoidosis," American Review of Respiratory Disease, vol. 135, no. 3, pp. 747-760, 1987.

[12] S. Kobak, "Sarcoidosis: a rheumatologist's perspective," Therapeutic Advances in Musculoskeletal Disease, vol. 7, no. 5, pp. 196205, 2015.

[13] O. P. Sharma, "Vitamin D, calcium, and sarcoidosis," Chest, vol. 109, no. 2, pp. 535-539, 1996.

[14] D. G. Gardner, "Hypercalcemia and sarcoidosis—another piece of the puzzle falls into place," American Journal of Medicine, vol. 110, no. 9, pp. 736-737, 2001.

[15] H. Reichel, H. P. Koeffler, R. Barbers, and A. W. Norman, "Regulation of 1,25-dihydroxyvitamin $\mathrm{D}_{3}$ production by cultured alveolar macrophages from normal human donors and from patients with pulmonary sarcoidosis," The Journal of Clinical Endocrinology \& Metabolism, vol. 65, no. 6, pp. 1201-1209, 1987.

[16] R. S. Mason, T. Frankel, Y. L. Chan, D. Lissner, and S. Posen, "Vitamin D conversion by sarcoid lymph node homogenate," Annals of Internal Medicine, vol. 100, no. 1, pp. 59-61, 1984.

[17] J. S. Adams, O. P. Sharma, M. A. Gacad, and F. R. Singer, "Metabolism of 25-hydroxyvitamin D3 by cultured pulmonary alveolar macrophages in sarcoidosis," The Journal of Clinical Investigation, vol. 72, no. 5, pp. 1856-1860, 1983.

[18] O. P. Sharma, J. Trowell, N. Cohen et al., "Abnormal calcium metabolism in sarcoidosis," in La Sarcoidose: Rapport, IV Conférence Internationale, J. Turiaf and J. Chabot, Eds., pp. 627632, Maison et Cie, 1967.
[19] E. Lebacq, H. Verhaegen, and V. Desmet, "Renal involvement in sarcoidosis," Postgraduate Medical Journal, vol. 46, no. 538, pp. 526-529, 1970.

[20] J. D. Reid and M. E. Andersen, "Calcium oxalate in sarcoid granulomas. With particular reference to the small ovoid body and a note on the finding of dolomite," American Journal of Clinical Pathology, vol. 90, no. 5, pp. 545-558, 1988.

[21] M. C. Iannuzzi, B. A. Rybicki, and A. S. Teirstein, "Sarcoidosis," The New England Journal of Medicine, vol. 357, no. 21, pp. 21532165, 2007.

[22] M. Brause, K. Magnusson, S. Degenhardt, U. Helmchen, and B. Grabensee, "Renal involvement in sarcoidosis-a report of 6 cases," Clinical Nephrology, vol. 57, no. 2, pp. 142-148, 2002.

[23] Z. Korzets, M. Schneider, R. Taragan, J. Bernheim, and J. Bernheim, "Acute renal failure due to sarcoid granulomatous infiltration of the renal parenchyma," American Journal of Kidney Diseases, vol. 6, no. 4, pp. 250-253, 1985.

[24] P. F. Williams, D. Thomson, and J. L. Anderton, "Reversible renal failure due to isolated renal sarcoidosis," Nephron, vol. 37, no. 4, pp. 246-249, 1984.

[25] S. Ikeda, T. Hoshino, and T. Nakamura, "A case of sarcoidosis with severe acute renal failure requiring dialysis," Clinical Nephrology, vol. 82, no. 4, pp. 273-277, 2014.

[26] M. G. Robson, D. Banerjee, D. Hopster, and H. S. Cairns, "Seven cases of granulomatous interstitial nephritis in the absence of extrarenal sarcoid," Nephrology Dialysis Transplantation, vol. 18, no. 2, pp. 280-284, 2003.

[27] I. Hilderson, S. Van Laecke, A. Wauters, and J. Donck, "Treatment of renal sarcoidosis: is there a guideline? Overview of the different treatment options," Nephrology, Dialysis, Transplantation, vol. 29, no. 10, pp. 1841-1847, 2014.

[28] J. Thumfart, D. Müller, B. Rudolph, M. Zimmering, U. Querfeld, and D. Haffner, "Isolated sarcoid granulomatous interstitial nephritis responding to infliximab therapy," American Journal of Kidney Diseases, vol. 45, no. 2, pp. 411-414, 2005. 


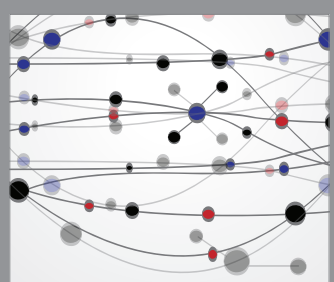

The Scientific World Journal
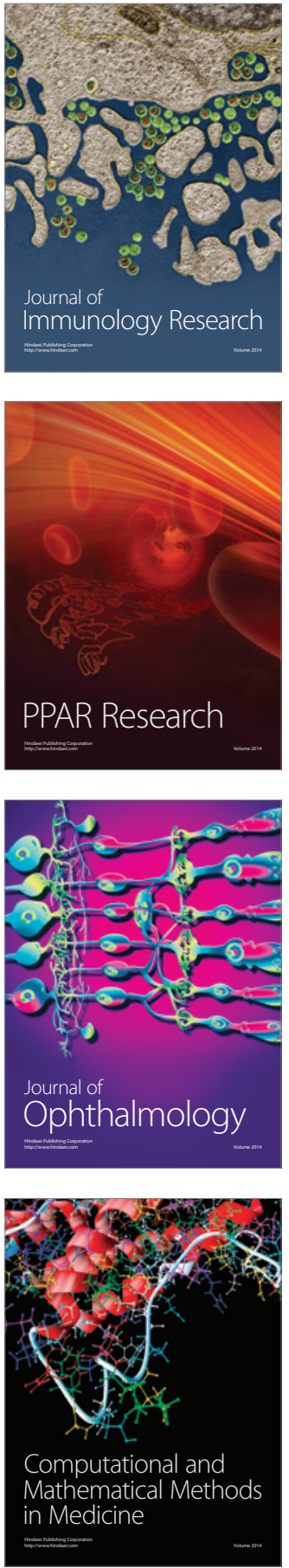

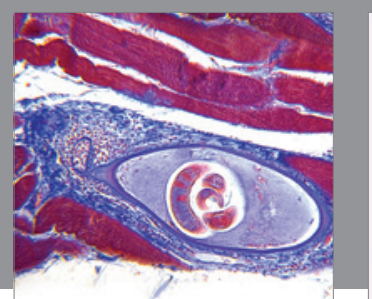

Gastroenterology Research and Practice

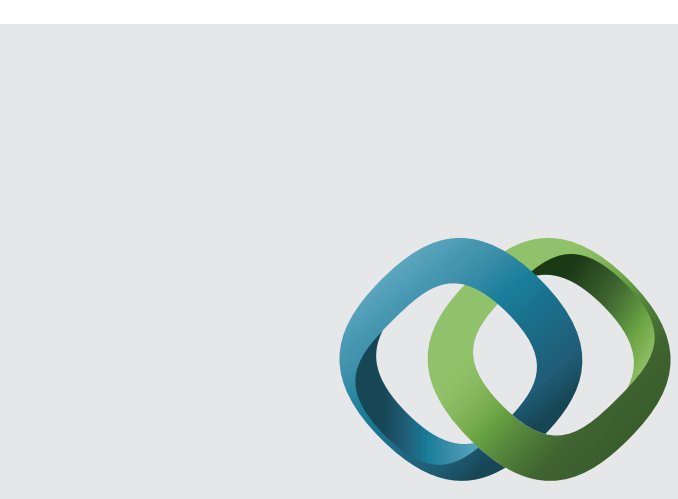

\section{Hindawi}

Submit your manuscripts at

http://www.hindawi.com
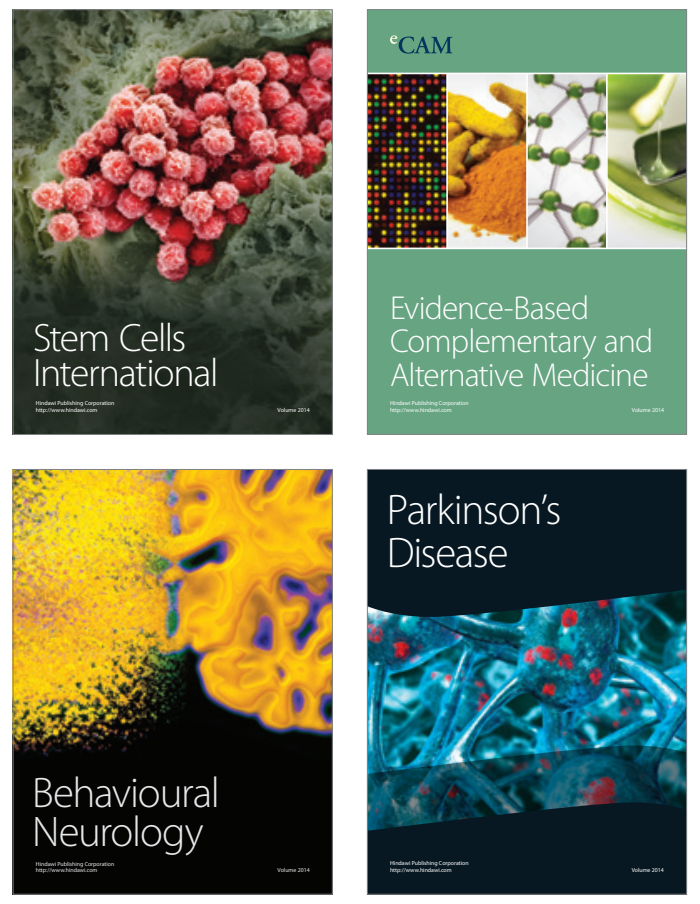
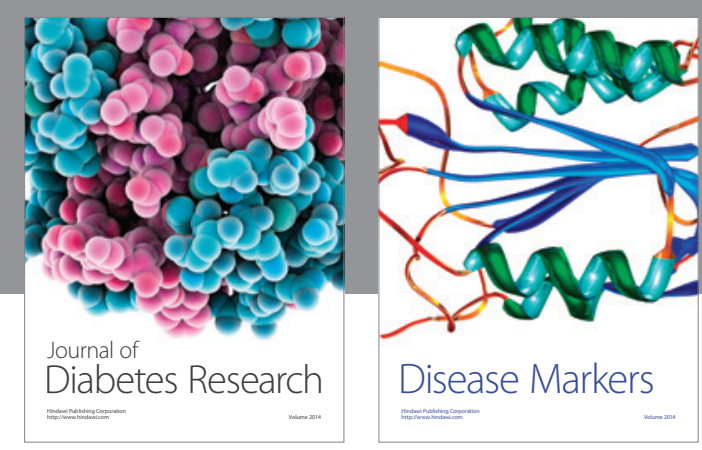

Disease Markers
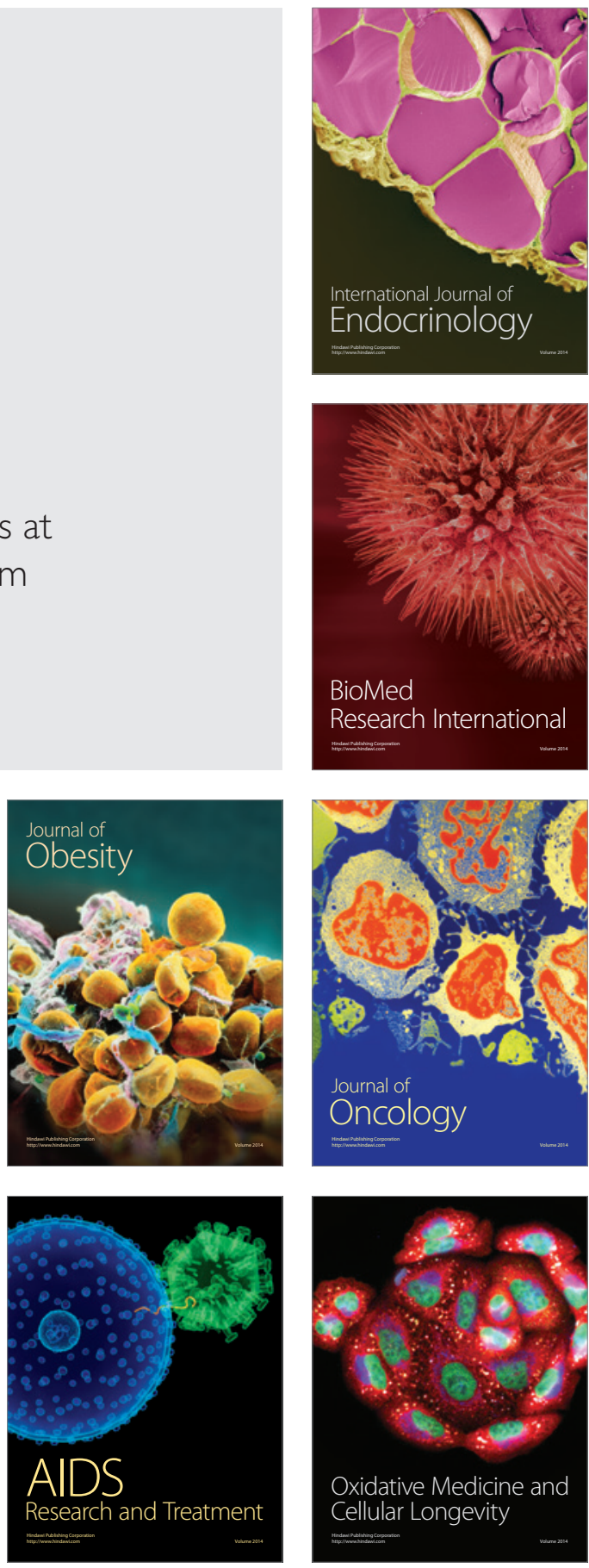